\title{
Evidence for unusual size dimorphism in a fossil ailurid
}

\author{
Ethan L. Fulwood and Steven C. Wallace
}

\begin{abstract}
A second nearly complete skeleton of the fossil ailurid Pristinailurus bristoli was recently recovered from the Hemphillian (late Miocene) Gray Fossil Site of northeast Tennessee. It appears to be significantly larger than the previously known skeleton of $P$. bristoli, which was surprising as the living red panda Ailurus fulgens is thought to be generally monomorphic, including between sexes. Here the presence of significant size difference in the geometric means of cranial and postcranial measurements and canine area in the two specimens of $P$. bristoli is tested relative to the distribution of size differences in intersex and intrasex pairs of $A$. fulgens. The presence of sexual dimorphism in these dimensions is also assessed in $A$. fulgens using t-tests. We report the first evidence of sexual dimorphism in both upper and lower canine area in A. fulgens. We also found evidence of significantly greater body size difference in the two specimens of $P$. bristoli than that present in $A$. fulgens. This could reflect a variety of causes, including the presence of multiple species or subspecies, a greater range of ecologically driven variability, or the presence of sexual dimorphism. We argue tentatively for sexual dimorphism as the most plausible explanation for the apparent size range of $P$. bristoli.
\end{abstract}

Ethan L. Fulwood. Department of Anthropology, University of Tennessee, Knoxville, Tennessee 37865 USA

Current Address: Department of Evolutionary Anthropology, Duke University, Durham, North Carolina 27708 USA ethan.fulwood@duke.edu

Steven C. Wallace. Department of Geosciences, Don Sundquist Center of Excellence in Paleontology, East Tennessee State University, Johnson City, Tennessee 37614 USA wallaces@mail.etsu.edu

Keywords: Ailuridae; size zimorphism; Pristinailurus; Gray fossil site

Submission: 1 December 2014. Acceptance: 5 August 2015

\section{INTRODUCTION}

Pristinailurus bristoli Wallace and Wang, 2004

is known from the Late Hemphillian (7-4.5 Ma)

Gray Fossil Site in northeast Tennessee (Wallace and Wang, 2004; Wallace, 2011a, 2011b), and is currently represented by numerous isolated teeth and bones and two relatively complete skeletons, which constitute the first associated skeletons from a fossil ailurine (Figure 1). Body mass estimates for

Fulwood, Ethan L. and Wallace, Steven C. 2015. Evidence for unusual size dimorphism in a fossil ailurid. Palaeontologia Electronica 18.3.45A: $1-6$

palaeo-electronica.org/content/2015/1313-dimorphism-in-pristinailurus

Copyright: September 2015 Society of Vertebrate Paleontology. This is an open access article distributed under the terms of the Creative Commons Attribution License (creativecommons.org/licenses/by/4.0/), which permits unrestricted use, distribution, and reproduction in any medium, provided the original author and source are credited. 


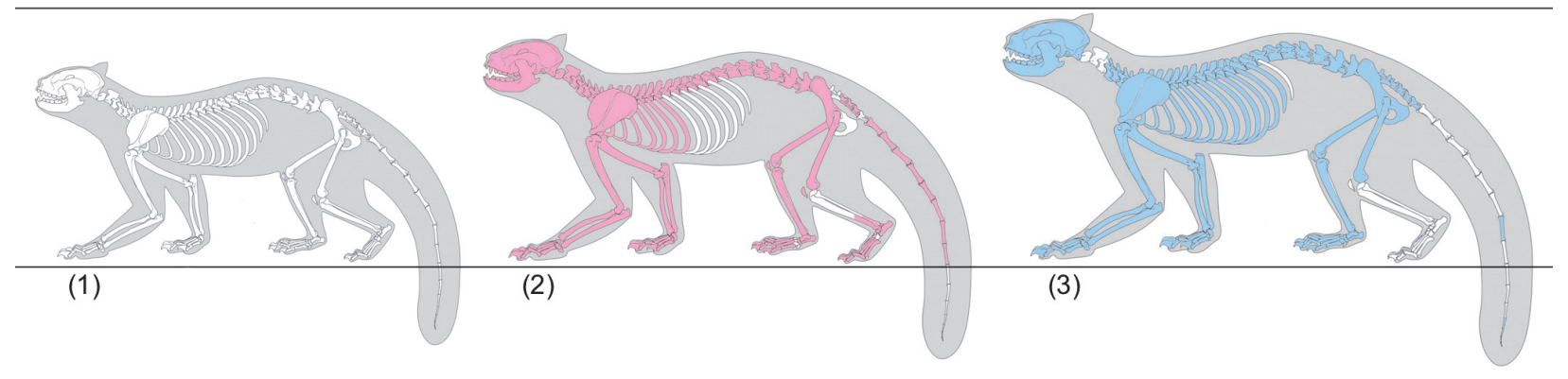

FIGURE 1. Size differences between Ailurus fulgens (1) and the two known skeletons of Pristinailurus bristoli (ETMNH 3596, 2; ETMNH 15000, 3). Shaded bones represent recovered elements from the two fossil skeletons.

the two specimens, calculated from the minimum breadth of the humerus following Christiansen and Harris (2005), differ by $52 \%$. The smaller of the two specimens (ETMNH 3596), a fully mature individual showing dental wear indicative of advanced age, is reconstructed at $8.25 \mathrm{~kg}$. Its skeleton is roughly $95 \%$ complete (Figure 1.2). The larger specimen (ETMNH 15000), a mature young adult with largely unworn teeth, is estimated at $15 \mathrm{~kg}$. It is roughly $75 \%$ complete (Figure 1.3 ). These two individuals do not therefore appear to indicate separate steps in an ontogenetic sequence. They also occur in relatively close stratigraphic and spatial proximity, and share diagnostic characters of the upper first molar (as defined by Wallace and Wang, 2004; see also Wallace, 2011a, 2011b). These include a first molar with length less than width; metaconule enlarged, strongly crest-like and isolated from the protocone; metastylar and parastylar cusps poorly developed to lacking; absence of both a mesostylar cusp and a discrete accessory cusp on posterior cingulum between the metastyle and metaconule; and retention of a lingual cingulum that merges with the hypocone at its posterior end.

In addition to its greater size, ETMNH 15000 exhibits greater robusticity in all long bone elements, with a humeral width/length ratio of 0.11 and femoral W/L ratio of 0.09 compared to ratios of 0.098 and 0.074 for ETMNH 3596, respectively. ETMNH 15000 displays a broader and deeper rostrum than ETMNH 3596, a trait often associated with sexual dimorphism in male musteloids and likely related to canine root depth (Ritke, 1990; Gittleman and Valkenburgh, 1997). ETMNH 15000 also displays wider and more massive zygomatic arches, associated with greater canine bite strength (Ritke, 1990).

We explore the magnitude of the apparent size difference between these two specimens by reference to the size distribution of the modern red panda, Ailurus fulgens, using pairwise comparisons of $A$. fulgens individuals. The fossil skeletal sample size of two is insufficient for robust inferential statistical analyses, but the percentage of randomly drawn pairs of $A$. fulgens as dimorphic as the two fossil specimens may be provisionally suggestive of the pattern present in Pristinailurus bristoli. If the two known specimens of $P$. bristoli differ more in size dimensions than $>95 \%$ of pairs of $A$. fulgens, this may suggest that the difference between ETMNH 3596 and ETMNH 15000 is biologically significant. This could reflect higher size variability in this fossil species than is present in the living ailurid, including variability due to sexual dimorphism, or indicate two size-differentiated species or subspecies present at the Gray site in the Hemphillian.

\section{METHODS AND MATERIALS}

\section{Sample}

Following Stefen and Heidecke (2012), standard cranio- and osteometric measurements were taken on 11 male and 11 female specimens of Ailurus fulgens (Field Museum of Natural History and Smithsonian National Museum of Natural History) and two specimens of Pristinailurus bristoli (East Tennessee State University and General Shale Brick Natural History Museum). Not all measurements were recordable on some specimens due to damage (see Table 1), so the total sample had to be subsampled for some measurements to calculate mean values.

\section{Institutional Abbreviations}

ETMNH - East Tennessee State University and General Shale Brick Museum of Natural History, Gray, Tennessee; FMNH - Field Museum of Natural History, Chicago, Illinois. 
TABLE 1. Table of $p$ values from each pairwise comparison by measurement and geometric mean. Asterisks indicate significant values $(<0.05)$. Bolded measurements indicate those discussed and interpreted in the text

\begin{tabular}{|c|c|c|c|c|c|}
\hline Measurements & Intersex $p$ & Intrafemale $p$ & Intramale $p$ & Male $n$ & Female $n$ \\
\hline Cranial length & 0.1111 & 0.125 & $0^{*}$ & 9 & 8 \\
\hline Basal length & 0.121 & 0.149 & 0.0741 & 9 & 11 \\
\hline Zygomatic breadth & $0^{*}$ & $0.0165^{*}$ & $0^{*}$ & 8 & 11 \\
\hline Upper carnassial length & 0.0505 & 0.0744 & 0.0988 & 9 & 11 \\
\hline Lower carnassial length & $0.0404^{*}$ & $0.0496^{*}$ & $0^{*}$ & 9 & 11 \\
\hline $\begin{array}{l}\text { Upper canine } \\
\text { mesiodistal breadth }\end{array}$ & 0.515 & 0.116 & 0.173 & 9 & 11 \\
\hline $\begin{array}{l}\text { Upper canine } \\
\text { buccolingual breadth }\end{array}$ & 0.354 & 0.0744 & 0.148 & 9 & 11 \\
\hline $\begin{array}{l}\text { Lower canine } \\
\text { mesiodistal breadth }\end{array}$ & 0.192 & $0.0413^{*}$ & $0.0494^{*}$ & 9 & 11 \\
\hline $\begin{array}{l}\text { Lower canine } \\
\text { buccolingual }\end{array}$ & 0.182 & $0.0331^{*}$ & $0.0370^{*}$ & 9 & 11 \\
\hline Facial length & 0.633 & 0.633 & 0.633 & 7 & 7 \\
\hline Bicanine breadth & $0.025^{*}$ & $0^{*}$ & $0.0313^{*}$ & 8 & 10 \\
\hline Biorbital breadth & $0^{*}$ & $0^{*}$ & $0^{*}$ & 8 & 10 \\
\hline Skull height & $0.0313^{*}$ & 0.0625 & $0^{*}$ & 8 & 8 \\
\hline Mandible length & 0.152 & 0.124 & 0.0988 & 9 & 11 \\
\hline Coronoid height & 0.152 & 0.174 & $0.0123^{*}$ & 9 & 11 \\
\hline Mandible height & 0.0556 & $0.04^{*}$ & $0^{*}$ & 9 & 10 \\
\hline Humerus length & $0^{*}$ & 0.08 & $0^{*}$ & 7 & 5 \\
\hline Humerus breadth & 0.0571 & $0.04^{*}$ & $0^{*}$ & 7 & 5 \\
\hline Femur length & $0.0286^{*}$ & 0.12 & $0^{*}$ & 7 & 5 \\
\hline Femur breadth & $0^{*}$ & $0^{*}$ & $0^{*}$ & 7 & 5 \\
\hline Upper canine area & 0.404 & 0.0826 & 0.148 & 9 & 11 \\
\hline Lower canine area & 0.152 & $0.0248^{*}$ & $0.0494^{*}$ & 9 & 11 \\
\hline Cranial geometric mean & 0.0667 & $0.0278^{*}$ & $0^{*}$ & 5 & 6 \\
\hline $\begin{array}{l}\text { Postcranial geometric } \\
\text { mean }\end{array}$ & $0^{*}$ & $0.04^{*}$ & $0^{*}$ & 7 & 5 \\
\hline
\end{tabular}

\section{Calculations}

A pairwise distance operation was employed

Geometric means of all cranial and postcranial measurements and the basal areas of the upper and lower canines (mesiodistal breadth $\mathrm{x}$ buccolingual breadth) were calculated for both the fossil and modern samples. To test for sexual dimorphism in Ailurus fulgens, the cranial and postcranial geometric means and upper and lower canine areas for each sex were compared using Welch's $t$-tests. One unusually robust female specimen, FMNH 60452, was more than 1.5 times above the interquartile range of the female sample in both upper and lower canine areas (Figure 2). Removing this individual from the analysis increased the significance of the $t$-tests, but as this did not impact the direction of the findings, analyses with FMNH 60452 included are reported. 
Lower Canine Area by Sex

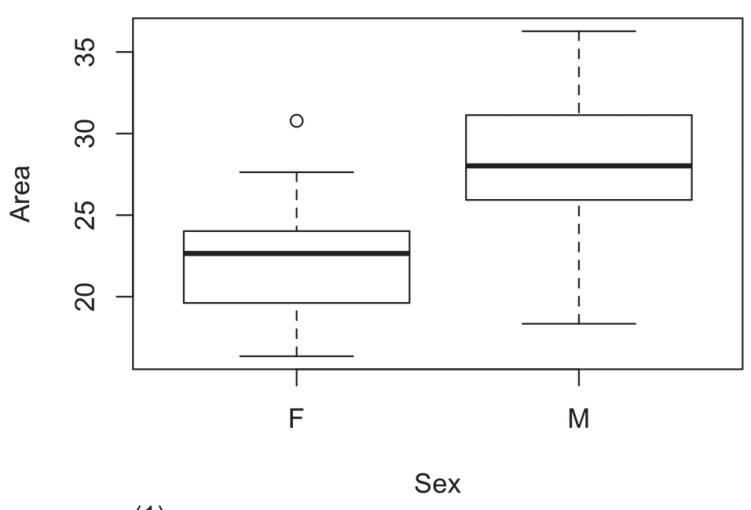

(1)

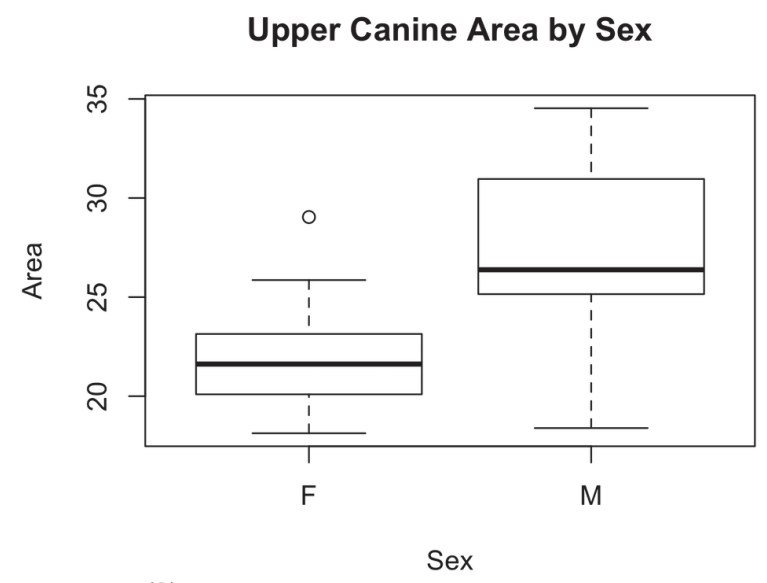

(2)

FIGURE 2. (1) Boxplot of Ailurus fulgens lower canine area by sex. (2) Boxplot of $A$. fulgens upper canine area by sex. Horizontal bars indicate the median, boxes represent middle quartiles, and error bars extend 1.5 times the interquartile range. Open circles beyond these bars indicate outliers.

15000 and ETMNH 3596 from the sample of Ailurus fulgens. All analyses were performed in the statistical programing environment $R$ ( $R$ Development Core Team, 2011).

\section{RESULTS}

Measurements are reported in Table 1. In Ailurus fulgens, both upper and lower canine areas were significantly different between sexes (Figure 2). No other measurements demonstrated significant sexual dimorphism. The geometric mean of the postcranial measurements of Pristinailurus bristoli was significantly more dimorphic than in the A. fulgens intersex $(p=0)$ and intrasex (male $p=0$, female $p=0.04$ ) pairs (Table 1 , Figure 3 ). Dimorphism in the cranial means of $P$. bristoli approached significance in comparison with the intersex pairs of $A$. fulgens $(p=0.0667)$ and was significant in comparison with the intrasex pairs (male $p=0$, female $p=0.0278$ ). Upper canine area was not significantly more different in $P$. bristoli than in A. fulgens in any of the comparisons. Lower canine area in $P$. bristoli was significantly more dimorphic than the intrasex pairs of $A$. fulgens (male $p=0.0494$, female $p=0.0248$ ). This likely reflects the presence of sexual dimorphism in these traits in $A$. fulgens and not necessarily monomorphism in $P$. bristoli.

\section{DISCUSSION}

This study presents the first evidence of significant canine sexual dimorphism in Ailurus fulgens. It supports, however, earlier suggestions that body size dimorphism is absent or negligible in this species (Roberts and Gittleman, 1984). As A. fulgens is known to exhibit a noncompetitive, promiscuous mating system in which male-male competition is rare or absent (Roberts and Gittleman, 1984), significant canine dimorphism is difficult to explain functionally. Canine dimorphism has been found to exhibit a strong phylogenetic correlation in other carnivorans (Gittleman and Valkenburgh, 1997), which may be the case here as well. Ailurids are nested within the Musteloidea (Schmidt-Kittler, 1981; Wolsan, 1993; Wang, 1997; Delisle and Strobeck, 2005; Sato et al., 2006; Fulton and Strobeck, 2006, 2007; Arnason et al., 2007; Yonezawa et al., 2007; Finarelli, 2008; Yu et al., 2008, 2011), the other families of which (Mustelidae, Mephitidae, and Procyonidae) are noted for their relatively high degree of canine sexual dimorphism (Weckerly, 1998). It may be probable that ailurids retained canine sexual dimorphism from a highly dimorphic last common ancestor with their sister clade, variously interpreted as procyonidae (Wang, 1997), or a larger clade of musteloids (Schmidt-Kittler, 1981; Wolsan 1993; Delisle and Strobeck, 2005; Sato et al., 2006; Fulton and Strobeck, 2006, 2007; Arnason et al., 2007; Yonezawa et al., 2007; Finarelli, 2008; Yu et al., 2008).

The postcranial geometric mean was significantly more dimorphic in the Pristinailurus bristoli pair than in both inter- and intra- sex pairs of Ailurus fulgens. This supports the presence of a significant body size difference between these two individuals, outside of the normal range of the modern red panda. The evidence for dimorphism pre- 
Distribution of Postcranial Geometric Means

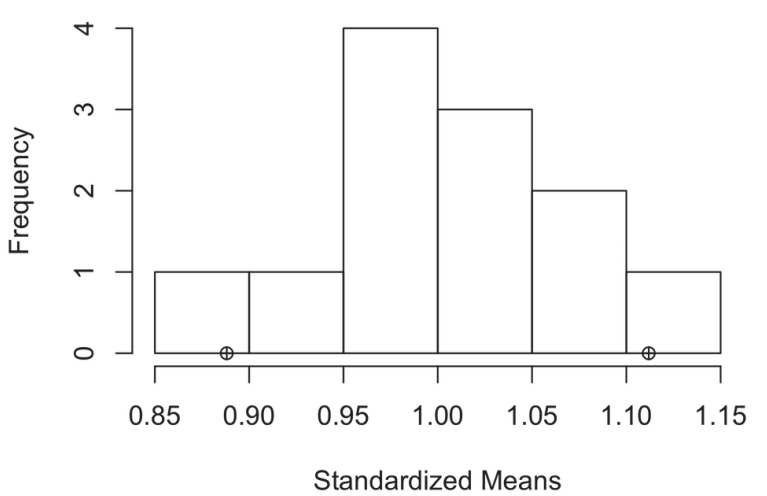

(1)
Distribution of Cranial Geometric Means

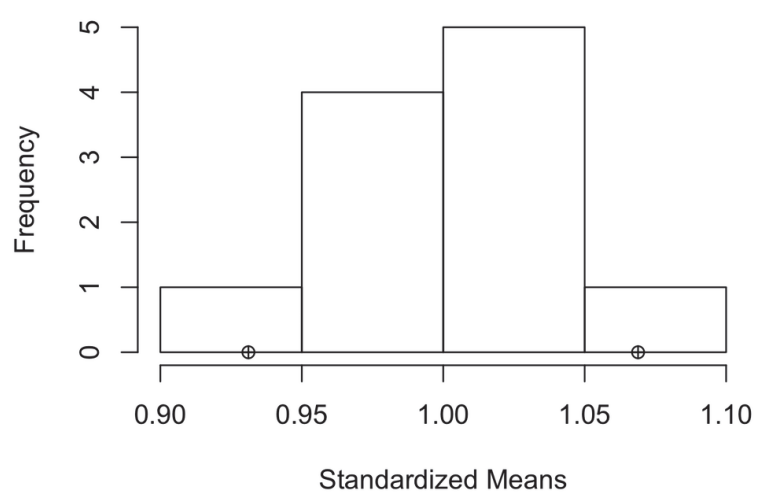

(2)

FIGURE 3. (1) Position of the standardized postcranial geometric means of the Pristinailurus bristoli within the standardized postcranial geometric mean distribution of a modeled Ailurus fulgens population. (2) Position of the standardized cranial geometric means of the $P$. bristoli pair within the standardized cranial geometric mean distribution of a modeled $A$. fulgens population.

sented here is necessarily tentative because of the small sample size and the limitations of the method employed. However, recent recovery (June 2013) of an isolated tibia that appears to fall within the size range of ETMNH 15000 and metatarsals closer to the size range of ETMNH 3596, but from different individuals, would appear to support the interpretation of two distinct morphotypes within this species.

The extent and causes of this dimorphism would likely be better resolved through the employment of traditional inferential statistics on body and canine size characters from a larger sample of Pristinailurus bristoli, which must await future discovery. We believe the close temporal and spatial relationship of these two specimens and the large number of shared traits argues against the presence of two species or subspecies, however. It is possible that $P$. bristoli exhibited a broader, but normally distributed, range of variation in size traits than Ailurus fulgens, perhaps for ecological reasons. However, the nature of the differences between the two specimens, in particular the depth of the rostrum and breadth of the zygomatics, suggest the strong possibility that the difference between the two specimens represents sexual dimorphism in body size in $P$. bristoli to a degree absent in the living red panda. Results from the lower canine comparisons may further support this hypothesis. These were non-significant intersexually but significant intrasexually. This pattern also prevailed in comparisons of upper canine breadth, although all of the $p$ values were $>0.05$. This sug- gests that the two individuals of $P$. bristoli differ from each other in canine cross-sectional area to a degree most comparable with a pair of male and female $A$. fulgens, which are shown here to be sexually dimorphic in this trait. Presence of sexual dimorphism in $P$. bristoli might suggest elevated levels of male intrasexual competition and could be related to the presence of a polygynous mating system, more typical of carnivorans than the promiscuous mating behavior reported for $A$. fulgens (Roberts and Gittleman, 1984; Gittleman and Van Valkenburg, 1997). More specimens of $P$. bristoli demonstrating a clear bimodal distribution in size would be necessary to confirm this hypothesis, however.

As the best-known fossil ailurine, Pristinailurus bristoli offers a unique opportunity to better understand the past diversity in body size variability of the Ailuridae, particularly if it does prove to demonstrate body size sexual dimorphism absent in the living species. This would better contextualize the evolution of the relatively unusual social system of Ailurus fulgens and support its interpretation as a derived character, perhaps related to its specialist arboreal, hypocarnivorous niche.

\section{ACKNOWLEDGEMENTS}

The authors would like to thank M. Salesa, B. Beatty, and K. Black for helpful feedback and editorial comments in the review process. We would also like to recognize the Smithsonian National Museum of Natural History, Field Museum of Natu- 
ral History, and East Tennessee State University and General Shale Brick Natural History Museum for access to their collections. This research was supported in part by the National Science Foundation (EAR-0958985 with REU Supplement) and ETSU Office of Research and Sponsored Programs.

\section{REFERENCES}

Arnason, U., Gullberg, A., Janke, A., and Kullberg, M. 2007. Mitogenomic analyses of caniform relationships. Molecular Phylogenetics and Evolution, 45:863-874.

Christiansen, P. and Harris, J.M. 2005. Body size of SmiIodon (Mammalia: Felidae). Journal of Morphology, 266:369-384.

Delisle, I. and Strobeck, C. 2005. A phylogeny of the Caniformia (order Carnivora) based on 12 complete protein-coding mitochondrial genes. Molecular Phylogenetics and Evolution, 37:192-201.

Finarelli, J.A. 2008. A Total Evidence Phylogeny of the Arctoidea (Carnivora: Mammalia): relationships among basal taxa. Journal of Mammalian Evolution, 15:231-259.

Fulton, T.L. and Strobeck, C. 2006. Molecular phylogeny of the Arctoidea (Carnivora): effect of missing data on supertree and supermatrix analyses of multiple gene data sets. Molecular Phylogenetics and Evolution, 41:165-181.

Fulton, T.L. and Strobeck, C. 2007. Novel phylogeny of the raccoon family (Procyonidae: Carnivora) based on nuclear and mitochondrial DNA evidence. Molecular Phylogenetics and Evolution, 43:1171-1177.

Gittleman, J. and Van Valkenburgh, B. 1997. Sexual dimorphism in the canines and skulls of carnivores: effects of size, phylogeny, and behavioural ecology. Journal of Zoology, 242:97-117.

Kramer, A., Donnelly, S., and Kidder, J. 1995. Craniometric variation in large-bodied hominoids: testing the single-species hypothesis for Homo habilis. Journal of Human Evolution, 29:443-462.

R Development Core Team. 2011. R Foundation for Statistical Computing.

Ritke, M. 1990. Sexual dimorphism in the raccoon (Procyon lotor): morphological evidence for intrasexual selection. American Midland Naturalist, 124:342-351.

Roberts, B.M.S. and Gittleman, J.L. 1984. Ailurus fulgens. Mammalian Species, 222:1-8.
Sato, J.J., Wolsan, M., Suzuki, H., Hosoda, T., Yamaguchi, Y., Hiyama, K., Kobayashi, M., and Minami, S. 2006. Evidence from nuclear DNA sequences sheds light on the phylogenetic relationships of Pinnipedia: single origin with affinity to Musteloidea. Zoological Science, 23:125-146.

Schmidt-Kittler, N. 1981. Zur Stammesgeschichte der marderverwandten Raubtiergruppen. Eclogae Geologicae Helvetiae, 74:753-801.

Smith, R.J. 1999. Statistics of sexual size dimorphism. Journal of Human Evolution, 36:423-458.

Stefen, C. and Heidecke, D. 2012. Ontogenetic changes in the skull of the European wildcat (Felis silvestris Schreber, 1777). Vertebrate Zoology, 62:281-294.

Wallace, S.C. 2011a. Advanced members of the Ailuridae ("Lesser" or Red Pandas - subfamily Ailurinae), p. 43-60. In Glatston, A. (ed.), The Forgotten Panda. William Andrew Publishing, London.

Wallace, S.C. 2011b. Bristol's Red Panda, Pristinailurus bristoli, p. 79-82. In Schubert, B.W. and Mead, J.I. (eds.), Gray Fossil Site Symposium, 10 Years of Research. West Press, Tucson.

Wallace, S.C. and Wang, X. 2004. Two new carnivores from an unusual late Tertiary forest biota in eastern North America. Nature, 431:2002-2005.

Wang, X. 1997. New cranial material of Simocyon from China, and its implications for phylogenetic relationship to the red panda (Ailurus). Journal of Vertebrate Paleontology, 17:184-198.

Weckerly, F. 1998. Sexual-size dimorphism : influence of mass and mating systems in the most dimorphic mammals. Journal of Mammalogy, 79:33-52.

Wolsan, M. 1993. Phylogeny and classification of early European Mustelida (Mammalia: Carnivora). Acta Theriologica, 38:345-384.

Yonezawa, T., Nikaido, M., Kohno, N., Fukumoto, Y., Okada, N., and Hasegawa, M. 2007. Molecular phylogenetic study on the origin and evolution of Mustelidae. Gene, 396:1-12.

Yu, L., Liu, J., Luan, P., Lee, H., Lee, M., Min, M.-S., Ryder, O.A, Chemnick, L., Davis, H., and Zhang, Y. 2008. New insights into the evolution of intronic sequences of the beta-fibrinogen gene and their application in reconstructing mustelid phylogeny. Zoological Science, 25:662-672.

Yu, L., Luan, P.T., Jin, W., Ryder, O.A., Chemnick, L.G., Davis, H.A., and Zhang, Y.P. 2011. Phylogenetic utility of nuclear introns in interfamilial relationships of Caniformia (Order Carnivora). Systematic Biology, 60:175-187. 